\title{
Fermentation and purification strategies for the production of betulinic acid and its lupane-type precursors in Saccharomyces cerevisiae
}

Czarnotta, Eik; Dianat, Mariam; Korf, Marcel; Granica, Fabian; Merz, Juliane; Maury, Jerome; Baallal Jacobsen, Simo Abdessamad; Förster, Jochen; Ebert, Birgitta E.; Blank, Lars Mathias

\section{Published in:}

Biotechnology and Bioengineering

Link to article, DOI:

10.1002/bit.26377

Publication date:

2017

Document Version

Peer reviewed version

Link back to DTU Orbit

Citation (APA):

Czarnotta, E., Dianat, M., Korf, M., Granica, F., Merz, J., Maury, J., Baallal Jacobsen, S. A., Förster, J., Ebert, B. E., \& Blank, L. M. (2017). Fermentation and purification strategies for the production of betulinic acid and its lupane-type precursors in Saccharomyces cerevisiae. Biotechnology and Bioengineering, 114(11), 2528-2538. https://doi.org/10.1002/bit.26377

\section{General rights}

Copyright and moral rights for the publications made accessible in the public portal are retained by the authors and/or other copyright owners and it is a condition of accessing publications that users recognise and abide by the legal requirements associated with these rights.

- Users may download and print one copy of any publication from the public portal for the purpose of private study or research.

- You may not further distribute the material or use it for any profit-making activity or commercial gain

- You may freely distribute the URL identifying the publication in the public portal 
Bioprocess Engineering and Supporting Technologies

Biotechnology and Bioengineering DOI 10.1002/bit.26377

Fermentation and purification strategies for the production of betulinic acid and its lupanetype precursors in Saccharomyces cerevisiae ${ }^{\dagger}$

Running title: Process engineering for microbial triterpenoid production

Eik Czarnotta ${ }^{1}$, Mariam Dianat ${ }^{1}$, Marcel Korf², Fabian Granica², Juliane Merz², Jérôme

Maury $^{3}$, Simo Abdessamad Baallal Jacobsen ${ }^{3}$, Jochen Förster ${ }^{3,4}$, Birgitta E. Ebert ${ }^{*}$, and

\section{Lars M. Blank ${ }^{1}$}

${ }^{1}$ iAMB - Institute of Applied Microbiology, ABBt - Aachen Biology and Biotechnology, RWTH Aachen University, Worringer Weg 1, 52074 Aachen, Germany

2 APT - Laboratory of Plant and Process Design, Department of Biochemical and Chemical Engineering, TU Dortmund University, Emil-Figge-Straße 70, Dortmund 44227, Germany

3 Technical University of Denmark, Novo Nordisk Foundation Center for Biosustainability, Kemitorvet, 2800 Kgs. Lyngby, Denmark

${ }^{4}$ Carlsberg A/S, 1799 Copenhagen, Denmark (current address)

*Correspondence:

Birgitta E. Ebert; birgitta.ebert@rwth-aachen.de; phone: +49 241 8026648; fax: +49 241

80622180

†This article has been accepted for publication and undergone full peer review but has not been through the copyediting, typesetting, pagination and proofreading process, which may lead to differences between this version and the Version of Record. Please cite this article as doi: [10.1002/bit.26377]

Additional Supporting Information may be found in the online version of this article. This article is protected by copyright. All rights reserved Received March 6, 2017; Revision Received May 24, 2017; Accepted July 2, 2017 


\begin{abstract}
Microbial production of plant derived, biologically active compounds has the potential to provide economic and ecologic alternatives to existing low productive, plant-based processes. Current production of the pharmacologically active cyclic triterpenoid betulinic acid is realized by extraction from the bark of plane tree or birch. Here, we reengineered the reported betulinic acid pathway into $S$. cerevisiae and used this novel strain to develop efficient fermentation and product purification methods. Fed-batch cultivations with ethanol excess, using either an ethanol-pulse feed or controlling a constant ethanol concentration in the fermentation medium, significantly enhanced production of betulinic acid and its triterpenoid precursors. The beneficial effect of excess ethanol was further exploited in nitrogen-limited resting cell fermentations, yielding betulinic acid concentrations of $182 \mathrm{mg} / \mathrm{L}$ and total triterpenoid concentrations of $854 \mathrm{mg} / \mathrm{L}$, the highest concentrations reported so far. Purification of lupane-type triterpenoids with high selectivity and yield was achieved by solid-liquid extraction without prior cell disruption using polar aprotic solvents such as acetone or ethyl acetate and subsequent precipitation with strong acids.

This study highlights the potential of microbial production of plant derived triterpenoids in S. cerevisiae by combining metabolic and process engineering. This article is protected by copyright. All rights reserved
\end{abstract}

Keywords: yeast, process development, downstream processing, pentacyclic triterpenoids, ethanol, betulinic acid 


\section{Introduction}

Pentacyclic triterpenoids received increasing attention over the last decade to exploit their biological activities, ranging from anti-inflammatory, anti-viral to anti-tumoral properties for applications in cosmetics, functional foods are as pharmaceuticals (Dzubak et al. 2006; Kuo et al. 2009; Zhang et al. 2015). A potentially anti-tumoral compound is betulinic acid, a secondary plant metabolite, which exhibits a selective cytotoxicity against melanoma and other cancer cells (Potze et al. 2016; Wick et al. 1999; Zuco et al. 2002). It is naturally found in the bark of higher plants including white-barked birch (Betula spp.) and plane (Platanus spp.) trees (Jäger et al. 2009; O'Connell et al. 1988) and its current production is based on a multistep extraction from pulverized bark (Puder et al. 2007). Additional purification steps are necessary, including distillation, filtration, adsorption, and recrystallization for obtaining pure betulinic acid. It is assumed that the demand of solvents for the extraction and energy consumption of distillation steps have a significant economic and ecologic impact (Ressmann et al. 2017). The recombinant production of betulinic acid with tailored microbes might therefore provide a sustainable alternative.

The yeast $S$. cerevisiae is a versatile production host and organism of choice for terpenoid synthesis. Expression of cytochrome P450 monooxygenases is more stable than in E. coli, cell compartments provide storage capacity for tri-, and tetraterpenoids (Gruchattka et al. 2013; Kirby and Keasling 2009; Wriessnegger and Pichler 2013), and a large toolset for genetic manipulation of $S$. cerevisiae is available (Maury et al. 2016). Moreover, the yeast's native ergosterol pathway provides 2,3-oxidosqualene, the common precursor for several cyclic triterpenoids (Moses et al. 2013). The heterologous betulinic acid pathway (Fig. 1) starts with the cyclization of 2,3oxidosqualene to lupeol by a oxidosqualene cyclase (OSC) and the subsequent oxygenation of lupeol to betulinic acid by a cytochrome P450 monooxygenase (CYP) and the corresponding cytochrome P450 reductase (CPR).

This article is protected by copyright. All rights reserved 
Recently, plant genes involved in synthesis of betulinic acid were identified and successfully expressed in S. cerevisiae (Fukushima et al. 2011; Huang et al. 2012). Only low betulinic acid titers of $0.1 \mathrm{mg} / \mathrm{L}$ were achieved with this first-generation strain (Huang et al. 2012) but further genetic improvements aiming for an increased flux into the mevalonate pathway and elevated cofactor supply enhanced betulinic acid titers to approximately 10 mg/L (Li and Zhang 2014; Li and Zhang 2015). Besides strain engineering, an efficient microbial production process requires the development of suitable fermentation and product recovery strategies. Indeed, cultivation mode, and applied feed strategy substantially contribute to the economic feasibility of the process. Glucose-limited exponential fed-batches are described for the production of the sesquiterpenes santalene and farnesene (Tippmann et al. 2016) and for ginsenosides, triterpenoid saponins (Dai et al. 2013). In contrast, a co-feed of glucose and ethanol was successfully applied for the production of the sesquiterpene amorphadiene, while titers achieved from glucose limited fed-batch were fairly low (Westfall et al. 2012). Maximal amorphadiene titers were achieved by adding pulses of pure ethanol (Paddon et al. 2013; Westfall et al. 2012). A similar beneficial effect of ethanol excess was described for the production of ergosterol, a sterol derived from 2,3-oxidosqualene (Tan et al. 2003). The development of fed-batch fermentations for the recombinant production of betulinic acid has not yet been described in literature and were the focus of this study. Suitable fermentation strategies and selective purification procedures were developed and evaluated, which enabled production of betulinic acid at high titers in recombinant yeast.

\section{Materials and Methods}

\section{Yeast strains, media and cultivation conditions}

Betulinic acid producing S. cerevisiae CEN.PK BA4 (BA4) was used in all performed experiments. The detailed strain construction is presented in the Supporting Information. Shake flask and bioreactor fermentations were carried out using a modified WM8 minimal medium (Lang and 
Looman 1995), which contained increased vitamin and trace element concentrations (myo-inositol $100 \mathrm{mg} / \mathrm{L}$, nicotinic acid $11 \mathrm{mg} / \mathrm{L}$, pyridoxine-HCl $26 \mathrm{mg} / \mathrm{L}$, thiamin-HCl $11 \mathrm{mg} / \mathrm{L}$, biotin $2.55 \mathrm{mg} / \mathrm{L}$, Ca-pantothenate $51 \mathrm{mg} / \mathrm{L}, \mathrm{p}$-amino benzoic acid $0.2 \mathrm{mg} / \mathrm{L} ; \mathrm{MgCl}_{2} \cdot 6 \mathrm{H}_{2} \mathrm{O} 250 \mathrm{mg} / \mathrm{L}$, $\mathrm{CaCl}_{2} \cdot 2 \mathrm{H}_{2} \mathrm{O} 104.5 \mathrm{mg} / \mathrm{L}, \mathrm{ZnSO}_{4} \cdot 7 \mathrm{H}_{2} \mathrm{O} 6.25 \mathrm{mg} / \mathrm{L}, \mathrm{FeSO}_{4} \cdot 7 \mathrm{H}_{2} 03.5 \mathrm{mg} / \mathrm{L}, \mathrm{CuSO} 4 \cdot 5 \mathrm{H}_{2} \mathrm{O} 0.4 \mathrm{mg} / \mathrm{L}$, $\mathrm{MnCl}_{2} \cdot 4 \mathrm{H}_{2} \mathrm{O} 0.1 \mathrm{mg} / \mathrm{L}, \mathrm{MnCl}_{2} \cdot 2 \mathrm{H}_{2} \mathrm{O} 1 \mathrm{mg} / \mathrm{L}, \mathrm{Na}_{2} \mathrm{MoO}_{4} \cdot 2 \mathrm{H}_{2} \mathrm{O} 0.5 \mathrm{mg} / \mathrm{L}, \mathrm{CoCl}_{2} \cdot 6 \mathrm{H}_{2} \mathrm{O} 0.3 \mathrm{mg} / \mathrm{L}$, $\mathrm{H}_{3} \mathrm{BO}_{3} 1 \mathrm{mg} / \mathrm{L}$, KI $0.1 \mathrm{mg} / \mathrm{L}$ ) and was complemented with $50 \mathrm{~g} / \mathrm{L}$ glucose. In the nitrogen depletion experiments, the $\mathrm{NH}_{4} \mathrm{Cl}$ concentration was reduced to $0.939 \mathrm{~g} / \mathrm{L}$ to enable nitrogen starvation. Working stocks of BA4 were prepared from 24 h cultures in WM8 medium, mixed with 40\% (v/v) glycerol in equal volumes and stored at $-80{ }^{\circ} \mathrm{C}$. Pre-cultures $(500 \mathrm{~mL}$ flask containing $50 \mathrm{~mL}$ medium) were inoculated with $1 \%(\mathrm{v} / \mathrm{v})$ from thawed working stock. Shake flask pre-cultivations were performed for $24 \mathrm{~h}$ in rotary shakers at $30^{\circ} \mathrm{C}, 200 \mathrm{rpm}$ and $5 \mathrm{~cm}$ amplitude. Main-cultures in shake flasks or bioreactors were inoculated with pre-cultures to an initial cell density of $0.08 \mathrm{gCDW}_{\mathrm{CW}} / \mathrm{L}$

\section{Fed-batch cultivation}

Batch bioreactor cultivations were performed in 1.3 L fermenters (BioFlow 115, New Brunswick, Eppendorf, Germany) with a working volume of $0.5 \mathrm{~L}$, an aeration rate of $1 \mathrm{vvm}, 30{ }^{\circ} \mathrm{C}$, and pH 6 controlled with $\mathrm{NH}_{4} \mathrm{OH}$ (10 M KOH for nitrogen-limited cultivations) and $\mathrm{H}_{3} \mathrm{PO}_{4}$. The dissolved oxygen (DO) level was kept above $30 \%$ using a stirring cascade. The batch medium was identical to the shake flask medium; during the feed phase, additional double concentrated WM8+ vitamin and trace element solution was added. For the pulse fed-batch, the DO signal was used to trigger substrate addition. When the DO signal exceeded a defined threshold (70\% DO), pure ethanol or glucose was pumped into the fermenter for a defined time. To avoid instant reactivation of the trigger when the DO signal drop exceeded the pumping time, reinitialization of the trigger was paused for $30 \mathrm{~min}$. The DO feed algorithm was implemented into the fermenter software 
BioCommand (New Brunswick, Eppendorf, Germany). For reasons of comparison, glucose pulses contained equimolar amounts of carbon as $25 \mathrm{~g} / \mathrm{L}$ ethanol, i.e. $32.6 \mathrm{~g} / \mathrm{L}$, and the broth volume was corrected by the added amount of water. The continuous ethanol feed was realized by monitoring the off-gas ethanol concentration with an ethanol sensor (BCP-EtOH, Bluesens, Germany) coupled to the I/O module of the fermenter (New Brunswick, Eppendorf, Germany). The fermenter software was used to control the ethanol feed pump via a feedback control loop.

Nitrogen-limited resting cell fermentations were performed by applying a glucose-limited exponential fed-batch to generate biomass as described by van Hoek et al. (2000). The growth rate

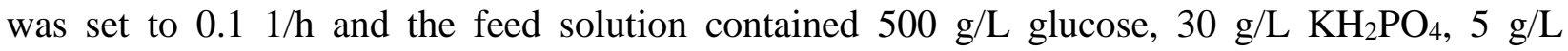
$\mathrm{MgSO}_{4} \cdot 7 \mathrm{H}_{2} \mathrm{O}$, and 2.5 times concentrated vitamins and trace elements. After the CDW reached approximately $60 \mathrm{~g} / \mathrm{L}$, cells were harvested by centrifugation, resuspended in $0.5 \mathrm{~L}$ fresh WM8+ medium without any nitrogen and carbon source, and transferred into a clean bioreactor. The resting cell fermentation was started by initiating the DO-triggered ethanol-pulse feed.

\section{Sample preparation}

During cultivation, samples were taken for optical density $\left(\mathrm{OD}_{600}\right)$, cell dry weight determination, and for quantification of extracellular metabolite and intracellular triterpenoid concentrations. Before sampling, bioreactors were carefully tilted to remove attachments from the inner reactor wall ensuring homogeneity. Samples were centrifuged for $10 \mathrm{~min}$ at 13,000 rpm. The cell free supernatant was analyzed using high performance liquid chromatography (HPLC) with UV and RI detection (see the Supporting Information for details). For terpenoid quantification, $800 \mu \mathrm{L}$ of fermenter broth was transferred into a $2 \mathrm{~mL}$ tube and stored at $-20^{\circ} \mathrm{C}$. For cell disruption and terpenoids extraction, $200 \mu \mathrm{L}$ glass beads $(0.5 \mathrm{~mm}), 80 \mu \mathrm{L} 1 \mathrm{M} \mathrm{HCl}$, and $800 \mu \mathrm{L}$ 80:20 chloroform:methanol mix were added and the tube was placed in a Mini-BeadBeater (BioSpec Products, USA) for $2 \mathrm{~min}$. The sample tube was then centrifuged for $10 \mathrm{~min}$ at 13,000 rpm and

This article is protected by copyright. All rights reserved 
$4{ }^{\circ} \mathrm{C}$ and $500 \mu \mathrm{L}$ of the lower organic phase was transferred into a conical HPLC glass vial. The organic phase was evaporated in a centrifugal evaporator (SpeedVac SC100, Savant, USA) for 15 min at $43{ }^{\circ} \mathrm{C}$, and dried terpenoids were resuspended in $100 \mu \mathrm{L}$ pyridine. Quantification of squalene, lupeol, betulin, betulinic aldehyde, and betulinic acid was performed using a reversed phase HPLC equipped with a charged aerosol detector. A detailed description of the applied HPLC methods is presented in the Supporting Information. Ammonium was quantified based on the method of Willis et al. (1996) using 24-well plates and a plate-reader (SynergyMX, BioTek, Germany).

\section{Determination of cell dry weight}

Cell dry weight (CDW) was either calculated by multiplying the $\mathrm{OD}_{600}$ signal with an experimentally pre-determined correlation factor or gravimetrically. For the gravimetrical method, a defined volume of the fermentation broth was centrifuged in pre-weighted tubes for $10 \mathrm{~min}$ at 13,000 rpm. The supernatant was discarded and the tubes with the pellet placed upside down on a cellulose sheet for $3 \mathrm{~min}$. The wet biomass was weighed and dried to constant mass at $105^{\circ} \mathrm{C}$ and weighed again to correlate the wet to dry biomass. The $\mathrm{OD}_{600}$ to $\mathrm{CDW}$ correlation factor was determined accordingly using cell suspensions with $\mathrm{OD}_{600}$ between 0.05 to 15 .

\section{Triterpenoid purification}

Triterpenoids were extracted from $0.08 \mathrm{~g}$ wet biomass. In case of liquid-suspension extraction (solvents used were n-amyl acetate, n-butyl acetate, 1-octanol, diethyl ether, and ethyl acetate) the solid material (biomass and crystals) was resuspended in $150 \mu \mathrm{L}$ water before extraction. The amount of solvent added depended on the particular phase ratio. The extraction was carried out in an Eppendorf Thermomixer comfort at 1,400 rpm and $25{ }^{\circ} \mathrm{C}$. The extract was separated by centrifuging the sample for $5 \mathrm{~min}$ at 13,000 rpm and withdrawing the extract phase with a syringe. The extraction time was defined as the time from solvent addition to extract removal.

This article is protected by copyright. All rights reserved 
To calculate product recovery yields, the initial content of betulin and betulinic acid in the sample was determined by extracting the triterpenoids twice with ethyl acetate at a phase ratio of 10 gsolvent/gCDw for $15 \mathrm{~h}$ at $25^{\circ} \mathrm{C}$. The first extract was analyzed directly while the second extract phase was concentrated prior to analysis using a rotary evaporator at $45{ }^{\circ} \mathrm{C}$ and 0.3 bar. The extraction purity was calculated using the ratio of peak area of betulin or betulinic acid to the total peak area in the HPLC chromatogram.

Extracts for the evaluation of adsorption or precipitation experiments were generated with an adapted protocol: For that, $40 \mathrm{~mL}$ fermentation broth was centrifuged for $10 \mathrm{~min}$ at 5,000 rpm. The supernatant was discarded and the tube placed upside down on cellulose paper for 5 min. Extraction was conducted in an overhead shaker (Grant Bio PTR 60) at $60 \mathrm{rpm}$ for $1 \mathrm{~h}$ at $25{ }^{\circ} \mathrm{C}$ with acetone at a phase ratio of 8 gsolvent/gCDw. The mixture was centrifuged for $3 \mathrm{~min}$ at 5,000 rpm and the extract phase withdrawn via a syringe.

For precipitation, $1 \mathrm{~mL}$ acetone extract was mixed with the antisolvent (water or acid) and the sample left at $25^{\circ} \mathrm{C}$ for $3 \mathrm{~h}$ if not stated otherwise. Precipitate and supernatant were separated by centrifugation for $30 \mathrm{~min}$ at 13,200 rpm and the supernatant was removed with a syringe. The precipitate was resolved with $1 \mathrm{~mL}$ acetone and mixed at $25^{\circ} \mathrm{C}$ and $1,400 \mathrm{rpm}$.

\section{Results}

\section{Performance of engineered betulinic acid producing $S$. cerevisiae strain in batch cultivations}

Multi copy genomic integration of the oxidosqualene cyclase gene AtLUP1 from Arabidopsis thaliana and the P450 monooxygenase CYP716All from Catharanthus roseus in combination with single, genomic integration of the P450 reductase encoding gene AtATR2 from Arabidopsis thaliana, overexpression of the native ERG1 and a truncated HMG1 (tHMG1) (Polakowski et al. 1998) in S. cerevisiae CEN.PK resulted in strain BA4, which accumulated betulinic acid as well as its precursors betulin and betulinic aldehyde (Fig. 2). Biomass formation followed the typical 
Crabtree-positive growth pattern on glucose. No specific accumulation of triterpenoids was observed during the glucose phase and volumetric titers increased only marginally. Once glucose was depleted, the cells started to consume ethanol and specific concentrations of squalene and betulin increased until stationary phase was reached and product accumulation ceased. In contrast, concentrations of betulinic aldehyde and betulinic acid per CDW were rather constant throughout the cultivation. This confirms prior findings from squalene overproducing $S$. cerevisiae CEN.PK expressing a truncated HMG gene, which likewise accumulated this triterpene only during the ethanol consumption phase (unpublished data).

In shake flask cultivations, specific concentrations of betulin and betulinic acid of up to $6.7 \mathrm{mg} / \mathrm{g}_{\mathrm{CDw}}$ and $2.1 \mathrm{mg} / \mathrm{g}_{\mathrm{CDw}}$ were achieved while the total triterpenoid concentration, i.e. the sum of all cyclic triterpenoid products including lupeol and betulinic aldehyde, reached $10.9 \mathrm{mg} / \mathrm{g}$ CDw. Batch cultivations run at different $\mathrm{pH}$ values revealed that a $\mathrm{pH}$ of 6 significantly shortened the fermentation time but resulted in lower total triterpenoid productivity compared to those achieved in shake flasks. During bioreactor cultivations accumulation of solid particles in a viscous layer on the inner reactor wall above the liquid level was observed (Fig. S1), which contained insoluble crystals and high amounts of triterpenoids. This phenomenon might have partially contributed to the concentration difference observed between shake flask and bioreactor experiments as these attachments might not be completely resuspended in the fermentation broth before sampling.

\section{Development of a fed-batch strategy}

To increase volumetric and specific titers of betulinic acid in BA4, different fed-batch fermentation strategies were evaluated. The application of carbon-limited feed modes (glucose, ethanol) resulted in low productivities and specific triterpenoid concentrations (data not shown) indicating the unsuitability of conventional carbon-limited fed-batch approaches for the production of triterpenoids. Next, feed strategies supplying excess ethanol were tested. The automated, repeated

This article is protected by copyright. All rights reserved 
addition of ethanol was triggered by an increase of the DO signal indicating ethanol depletion. Application of $25 \mathrm{~g} / \mathrm{L}$ ethanol pulses resulted in a substantial increase of specific and volumetric product titers when compared to batch fermentations (Fig. 3A). Betulin was still the main triterpenoid (52\% of the total triterpenoids), followed by betulinic aldehyde (22\%), betulinic acid (18\%), and lupeol (8\%). For squalene, both specific and volumetric concentrations reached a maximum at 43 Interestingly, product formation reached a plateau after addition of the third ethanol pulse at a rather low biomass concentration of $34 \mathrm{~g} / \mathrm{L}$ Cessation of both product formation and cell growth was observed in all fed-batch fermentations performed with BA4, and HPLC data from samples taken after the third pulse showed increasing acetate concentrations indicating increased cell stress (Fig. 3C). Application of glucose pulses was less efficient than ethanol. Although specific titers and productivities for betulinic acid were in the same range compared to the above described ethanol-pulse feed, titers of the other triterpenoids were reduced by more than 1.5-fold (Table I). In order to investigate the influence of the ethanol pulse concentrations on product formation, different ethanol-pulse feeds, ranging from 5-30 g/L, were tested. Higher pulse concentrations resulted in increased specific betulin titers while accumulation of betulinic aldehyde and acid was not enhanced and their specific concentrations remained almost constant.

\section{Application of a controlled ethanol feed}

The DO-triggered pulse fed-batch enabled the production of betulinic acid at high productivities by exploiting the beneficial effect of excess ethanol concentrations on strain performance. However, frequent transitions between starving and metabolizing states might have a negative effect on productivity. To maintain a constant ethanol level in the fermenter broth, we realized a controlled feed using the off-gas ethanol signal as input for a control loop regulating the ethanol feed rate. The controlled feed was deployed at the late phase of the initial glucose batch and the ethanol concentration was set to $7 \mathrm{~g} / \mathrm{L}$ (Fig. 3B and D). Since no substrate limitation occurred, BA4

This article is protected by copyright. All rights reserved 
cells initially grew with the maximal growth rate on ethanol $(0.071 / \mathrm{h})$. Triterpenoid titers with betulin as main product increased linearly until the above described product plateau was reached after $72 \mathrm{~h}$ of cultivation (Fig. 3B). The betulinic acid concentration of $44 \mathrm{mg} / \mathrm{L}$ was slightly lower compared to the pulsed fed-batch but concentrations and productivities of the remaining triterpenoids were increased and a total pentacyclic triterpenoid concentration of $346 \mathrm{mg} / \mathrm{L}$ was reached within $72 \mathrm{~h}$. Extracellular acetate levels increased exceedingly rapidly to $10 \mathrm{~g} / \mathrm{L}$ coinciding with ceasing cell growth and product synthesis (Fig. 3D). Overall, regulating the ethanol level in the fermenter at a constant concentration allowed a fermentation devoid of rapid changes in stirring speed, resulting in increased product titer and product yield (Table II).

\section{Effect of nitrogen limitation on triterpenoid titers}

As triterpenoid production has to compete for carbon, redox and energy cofactors during cell growth, restriction of biomass synthesis by nitrogen limitation might enhance the flux into terpenoid synthesis (Shang et al. 2006). To evaluate this, two strategies were pursued: growth into nitrogen depletion and resting cell fermentations, in which cells from a glucose-limited exponential fed-batch were transferred into nitrogen-free fresh medium. Both strategies were coupled with the ethanol-pulse feed. Nitrogen depletion was achieved by reducing the initial nitrogen content to a level limiting growth above a biomass concentration of 6 gcDw/L. Notably, product ratios shifted towards betulinic acid, being the main triterpenoid produced under this condition (Fig. 4A), however, triterpenoid productivities were comparably low due to a low cell concentration. In contrast, maximal betulin and betulinic acid concentrations of $464 \mathrm{mg} / \mathrm{L}$ and $182 \mathrm{mg} / \mathrm{L}$ and a total triterpenoid titer of $854 \mathrm{mg} / \mathrm{L}$ were obtained in resting cell fermentation, the highest titers for the lupane-type triterpenoids reported so far (Fig. 4B). Carry-over of low amounts of ammonia from the fed-batch medium resulted in further growth within the first $4 \mathrm{~h}$ of the resting cell cultivation. During this micro-nitrogenous conditions and in the first $4 \mathrm{~h}$ following the exhaustion of exogenous

This article is protected by copyright. All rights reserved 
nitrogen sources, terpenoid synthesis was highest. The application of a nitrogen-limited exponential feed with ethanol excess was also investigated within this work (data not shown), however specific and volumetric triterpenoid titers were comparably low.

\section{Development of a downstream process for product recovery}

Separate analysis of cell pellet and supernatant revealed that only minor amounts of the triterpenoids were secreted into the medium. Interestingly, this intracellular accumulation of the product contrasts with previous findings by Zhou et al. (2016), who reported detection of these products in the medium. The intracellular product accumulation observed in our study motivated the evaluation of downstream process variants. Chemical and mechanical cell disruption techniques, preceding the extraction step, were initially tested to facilitate product extraction from the solid fraction, i.e., biomass and crystals. However, cell disruption did not affect extraction efficiency but increased impurity contents and was omitted in further experiments. Extraction strategies for product recovery from the solid fraction were liquid-suspension extractions, in which the water-immiscible solvents and the fermentation broth form distinct phases, and classical solidliquid extraction, in which water and solvent are completely miscible. Suitable extraction solvents were assessed based on solubility parameters estimated by the method of Bergs et al. (2013) or mined by extensive literature screening. In total, eight solvents were evaluated, including diethyl ether, which is used in industrial extraction of betulinic acid from tree bark, (Table SII). The polar aprotic solvents ethyl acetate and acetone used for liquid-suspension extraction and solid-liquid extraction, respectively, gave highest yields (Fig. 5A). This phenomenon of preferential distribution of nonpolar compounds in polar solvents has been described before (Cheng et al. 2011; Co et al. 2009; Follegatti-Romero et al. 2010; Tang et al. 2014) and explained by a favored entropic state of the molecule in the solvent. As a positive side-effect reduced co-extraction of other nonpolar metabolites in these polar solvents resulted in high purities (ratio of peak area of betulinic

This article is protected by copyright. All rights reserved 
acid to the sum of all peak areas of the components present in the chromatogram) compared to less polar solvents. For both, ethyl acetate and acetone, the kinetics of extraction at $25{ }^{\circ} \mathrm{C}$ was determined and the influence of different phase ratios on recovery yield and purity evaluated (Fig. 6A-D). A phase ratio of 4 gsolvent/gCDW and extraction time of $5 \mathrm{~h}$ with ethyl acetate and a phase ratio of 6 gsolvent/gCDW and $1 \mathrm{~h}$ extraction time for extractions with acetone turned out to be optimal and were used in all further experiments. As the extraction screening was done in early stages of the project when the fermentation strategy was still under optimization, some experiments were repeated with broth of the optimized fermentation protocol. The extraction performance for both solvents, but especially for acetone, increased. Yields of $90 \pm 4 \%$ for ethyl acetate and $91 \pm 2 \%$ for acetone with similar purities of betulinic acid were achieved while betulin was recovered to $90 \pm 2 \%$ and $82 \pm 3 \%$ with ethyl acetate and acetone, respectively.

Despite differences in polarity of the triterpenoids betulin and betulinic acid, assessed from 1octanol/water partition coefficients (betulin: 9.01, betulinic acid: 8.94) estimated with ACD/Chemsketch freeware, none of the screened extraction solvents was suited to selectively extract the acid. Equally, an additional purification step of adsorption/desorption with both ethyl acetate and acetone extracts using different adsorber materials as described in Winkelnkemper et al. (2011) turned out to be nonselective and gave low yields (data not shown). As the solubility of betulinic acid and other hydrophobic triterpenoids is $\mathrm{pH}$-dependent and decreases at low pH (Jäger et al. 2007), we evaluated polar acetone-miscible antisolvents enabling precipitation for product recovery. We investigated mono-, di-, and tribasic inorganic (hydrochloric, sulfuric, and phosphoric acid) and organic acids (formic, acetic, citric, and oxalic acid) of different molarities (0.1 $\mathrm{M}$ and $1 \mathrm{M}$ ) and water at phase ratios ranging from 0.3 to $0.9 \mathrm{~mL}$ Acid $/ \mathrm{mL}_{\text {Extract. For all }}$ antisolvents investigated, a phase ratio above $0.7 \mathrm{~mL}_{\text {Acid }} / \mathrm{mL}_{\text {Extract }}$ favored a high recovery of betulinic acid while the molarity of the acid did not significantly affect the recovery or purity of

This article is protected by copyright. All rights reserved 
the precipitate. Precipitation with neither of the antisolvents tested was selective as betulinic acid and betulin were recovered with similar yields (Fig. 5B). In addition, no trend in recovery was observed for acids of different acidity or of organic or inorganic origin. Interestingly, precipitation with hydrochloric and sulfuric acid resulted in yields above $100 \%$ for betulin and lupeol. Inspection of the HPLC chromatograms of resolved precipitate revealed that in those samples treated with 0.9 $\mathrm{M}$ and $5 \mathrm{M}$ hydrochloric acid $(\mathrm{HCl})$ four peaks diminished (0.9 $\mathrm{M} \mathrm{HCl})$ or almost disappeared (5 M HCl) while the peaks of reference triterpenoids increased (Fig. 7). LC-MS measurement of the crude extract pointed to the presence of an additional hydroxy group at C-20 position or the presence of an acetyl group at position C-3 (Figure S5-S8). The unspecific cyclization of 2,3oxidosqualene by LUP1 is reported to yield lupanediol (3,20-dihydroxylupane) as a side product (Salmon et al. 2016; Segura et al. 2000), which is subsequently oxidized by CYP716Al1 to form the corresponding betulin-diols. In addition to that, we hypothesize that the alcohol acetyltransferase ATF1, involved in terpenyl acetate synthesis (Steyer et al. 2013; Verstrepen et al. 2004), acted on the lupane-type triterpenoids yielding its acetate forms. The acidic environment during the precipitation step likely caused the dehydration of the tertiary hydroxy group of the triterpenoid diols or the deacetylation of the triterpenoid esters. Further optimization of the precipitation process by adjusting phase ratio and precipitation time resulted in betulin recoveries of almost 200\% using $1 \mathrm{M} \mathrm{HCl}$ (phase ratio of $1.2 \mathrm{~mL}_{\text {Acid }} / \mathrm{mL}_{\text {Extract, }} 3$ h resting time, Table III). For water, a phase ratio of $1 \mathrm{~mL}$ Acid $/ \mathrm{mL}_{\text {Extract }}$ (high recovery and low volume of antisolvent) was favorable and the precipitate could be separated directly as no hydrolytic reaction occurred. Washing of the precipitate with water or hexane as proposed by Dräger et al. (2001) was tried but resulted in substantial product loss and only marginally increased purity. Despite the low purity, the developed downstream process is very promising as $78 \%$ or $95 \%$ of the betulinic acid were recovered from the fermentation broth and triterpenoids betulin, betulinic acid and lupeol were 
enriched to $64 \%$ and $72 \%$ using water or $\mathrm{HCl}$, respectively. For further purification, chromatographic separation is recommended for which the analytical method used here might be transferred to preparative scale.

\section{Discussion}

\section{Ethanol is the preferred carbon source for triterpenoid production}

In accordance with studies investigating yeast-based artemisinin and ergosterol production (Paddon et al. 2013; Tan et al. 2003; Westfall et al. 2012), feeding of ethanol was beneficial for cyclic triterpenoid production. Reasons for this improvement might be the elevated supply of the common precursor acetyl-CoA or the redox cofactor NADPH, of which $18 \mathrm{~mol}$ and $17 \mathrm{~mol}$ are required to synthesize one mol of betulinic acid. The acetyl-CoA synthetase gene ASC1 is subject to glucose repression but derepressed during ethanol oxidation (Chen et al. 2012; Kratzer and Schuller 1997; van den Berg et al. 1996) during which $\mathrm{NADP}^{+}$is simultaneously reduced by aldehyde dehydrogenase Ald6 activity. Also, slow growth on ethanol or complete growth rest might have been advantageous for accumulation of triterpenoids as has been reported for ergosterol (Arnezeder and Hampel 1990). However, as the precursor squalene accumulated during ethanol oxidation, redox cofactor availability rather than acetyl-CoA supply might have been limiting betulinic acid synthesis. The application of nitrogen-limitation for non-growing cell fermentations might have increased the NADPH availability for product synthesis. In addition to that, an increased redox cofactor regeneration might be achieved by introducing an additional NADPH generating reaction, e.g. a mutated $\mathrm{NADP}^{+}$-dependent 2,3-butanediol dehydrogenase gene $m B D H 1$ and co-feeding of its substrate acetoin, reported by Li et al. (2015) to improve betulinic acid synthesis.

High concentration of ethanol exerts cell stress, to which $S$. cerevisiae responds by stimulating ergosterol synthesis (del Castillo Agudo 1992; Teixeira et al. 2009). This metabolic adaptation 
might boost the availability of the common precursor 2,3-oxidosqualene explaining the 2-times higher total triterpenoid productivities and the 2.4-fold increase in carbon yield in ethanol-pulse fed-batches compared to experiments with glucose as carbon source (Table I and II).

Cessation of product formation and growth in prolonged fermentations at low cell concentrations and below the maximal triterpenoid load per cell observed under nitrogen-limitation indicates decreased cell viability due to accumulation of toxic intermediates or reactive oxygen species as has been reported for production of farnesene and artemisinic acid (Paddon et al. 2013; Sandoval et al. 2014). Formation of reactive oxygen species through uncoupling of NADPH oxidation and substrate oxidation is commonly observed in monooxygenase-type reactions and can severely affect cell viability by damaging proteins and destabilizing membranes (Blank et al. 2010; Farrugia and Balzan 2012; Perrone et al. 2008; Zangar et al. 2004). Overexpression of cytosolic catalase encoding CTT1 was shown to increase viability of artemisinic acid producing $S$. cerevisiae (Paddon et al. 2013) and might equally be a measure to increase the activity of triterpenoid producing yeast.

\section{Feedback-controlled ethanol feed enhances product yield}

The DO-triggered ethanol feed, similar to the control strategy presented by Paddon et al. (2013), was easy to set up and yielded good productivities. The positive effect of high ethanol concentrations in the culture medium outpaced the carbon loss from ethanol evaporation and product yields on ethanol slightly improved with increasing pulse concentrations. A second drawback of the pulse feed are the rapid metabolic switches between starvation and ethanol metabolism, potentially resulting in paused terpenoid synthesis and lowering productivity and product yield. This was overcome by controlling the ethanol concentration at a constant level, which resulted in significantly increased substrate yield and productivity justifying additional equipment costs for the required ethanol off-gas sensor coupled to the control-loop. Further testing 
of different ethanol concentrations is required for finding an optimum between triterpenoid yield, productivity and evaporation.

\section{Multi-step oxygenation of lupeol in S. cerevisiae CEN.PK BA4 limits betulinic acid synthesis}

The accumulation of the pathway intermediate squalene to fairly high levels pinpoints to enzymatic limitations in the downstream betulinic acid synthesis pathways, demanding optimization of respective enzyme activities. However, the main bottleneck for betulinic acid production was the catalytic activity of the P450 monooxygenase (CYP716Al1) because the three-step oxidation of lupeol to betulinic acid was insufficient. Adaptation of the fermentation condition increased specific betulin concentration while betulinic acid accumulation stayed constant. Full conversion might require the integration of additional suitable alcohol and aldehyde dehydrogenases as reported for artemisinin production (Paddon et al. 2013).

\section{Solid-liquid extraction and precipitation eases recovery of lupane-type triterpenoids}

Good recoveries of the pentacyclic triterpenoids from the cell pellet were achieved by extraction with either ethyl acetate or acetone, followed by a precipitation step. With the tested extractants, solid-liquid extraction generally performed better than liquid-suspension extraction, as the latter forms a two-liquid phase system, in which the water phase shields the biomass preventing direct access. Liquid-suspension extraction with ethyl acetate was one exception with similar performance as solid-liquid extraction with acetone, but had slower extraction kinetics probably due to mass transfer limitations in the two-liquid phase system. Another advantage of acetone based extraction is its time-independent selectivity, which is in contrast to ethyl acetate extraction for which the purity of betulinic acid decreased at prolonged extraction durations. One drawback of the use of acetone is the relatively low solubility of triterpenoids in this solvent as the necessity of high phase ratios to achieve efficient extraction (Cheng et al. 2011) might increase costs for solvent recovery in a large-scale process.

This article is protected by copyright. All rights reserved 
Although high product recoveries were achieved, the established downstream process was not selective for betulinic acid. Consequently, for the establishment of a production process a further chromatographic or crystallization step will be necessary. These elaborate purification steps are economically acceptable as both lupeol and betulin are valuable products.

\section{Conclusion}

The developed fermentation and purification strategies provide a suitable basis for upstream and downstream processing for the microbial synthesis of triterpenoids. Triterpenoid titers and productivities were improved by more than 5-fold and 4-fold, respectively compared to simple shake flask experiments and are, so far, the highest triterpenoid productivities reported for recombinant S. cerevisiae. Recoveries above $80 \%$ of betulin and betulinic acid from the fermentation broth were possible applying a simple downstream procedure. Low specific productivity of the engineered strain and potential toxic effects resulting in total cessation of triterpenoid synthesis after prolonged fermentation times are the main bottlenecks for a competitive microbial betulinic acid production. Further metabolic engineering of the production host is required to increase specific productivity and product specificity, and to either maximize the triterpenoid load of the cell or enable product secretion.

This article is protected by copyright. All rights reserved 


\section{Acknowledgements}

We thank Dr. Kilian Smith from the Institute for Environmental Research RWTH Aachen University for performing the LC-MS measurements. We acknowledge financial support by the Deutsche Bundesstiftung Umwelt (Grant ID AZ13272).

\section{Conflict of Interest Disclosure}

The authors declare no conflict of interest. 


\section{References}

Arnezeder C, Hampel WA. 1990. Influence of growth rate on the accumulation of ergosterol in yeast-cells. Biotechnol Lett 12(4):277-282.

Bergs D, Merz J, Delp A, Joehnck M, Martin G, Schembecker G. 2013. A standard procedure for the selection of solvents for natural plant extraction in the early stages of process development. Chem Eng Technol 36(10):1739-1748.

Blank LM, Ebert BE, Buehler K, Bühler B. 2010. Redox biocatalysis and metabolism: molecular mechanisms and metabolic network analysis. Antioxid Redox Signal 13(3):349-394.

Chen Y, Siewers V, Nielsen J. 2012. Profiling of cytosolic and peroxisomal acetyl-CoA metabolism in Saccharomyces cerevisiae. PLoS One 7(8):e42475.

Cheng Y, Shao Y, Yan W. 2011. Solubilities of betulinic acid in thirteen organic solvents at different temperatures. J Chem Eng Data 56(12):4587-4591.

Co M, Koskela P, Eklund-Åkergren P, Srinivas K, King JW, Sjöberg PJR, Turner C. 2009. Pressurized liquid extraction of betulin and antioxidants from birch bark. Green Chem 11(5):668-674.

Dai Z, Liu Y, Zhang X, Shi M, Wang B, Wang D, Huang L, Zhang X. 2013. Metabolic engineering of Saccharomyces cerevisiae for production of ginsenosides. Metab Eng 20(0):146-156.

del Castillo Agudo L. 1992. Lipid content of Saccharomyces cerevisiae strains with different degrees of ethanol tolerance. Appl Microbiol Biotechnol 37(5):647-651.

Draeger B, Galgon T, Neubert R, Wohlrab W; 2001. Method of producing betulinic acid. US patent 6,175,035 B1.

Dzubak P, Hajduch M, Vydra D, Hustova A, Kvasnica M, Biedermann D, Markova L, Urban M, Sarek J. 2006. Pharmacological activities of natural triterpenoids and their therapeutic implications. Nat Prod Rep 23(3):394-411.

Farrugia G, Balzan R. 2012. Oxidative stress and programmed cell death in yeast. Front Oncol 2:64.

Follegatti-Romero LA, Lanza M, da Silva CAS, Batista EAC, Meirelles AJA. 2010. Mutual solubility of pseudobinary systems containing vegetable oils and anhydrous ethanol from (298.15 to 333.15) K. J Chem Eng Data 55(8):2750-2756.

Fukushima EO, Seki H, Ohyama K, Ono E, Umemoto N, Mizutani M, Saito K, Muranaka T. 2011. CYP716A subfamily members are multifunctional oxidases in triterpenoid biosynthesis. Plant Cell Physiol 52(12):2050-2061.

Gruchattka E, Hadicke O, Klamt S, Schutz V, Kayser O. 2013. In silico profiling of Escherichia coli and Saccharomyces cerevisiae as terpenoid factories. Microb Cell Fact 12:84.

Huang L, Li J, Ye H, Li C, Wang H, Liu B, Zhang Y. 2012. Molecular characterization of the pentacyclic triterpenoid biosynthetic pathway in Catharanthus roseus. Planta 236(5):15711581.

Jäger S, Trojan H, Kopp T, Laszczyk MN, Scheffler A. 2009. Pentacyclic triterpene distribution in various plants-rich sources for a new group of multi-potent plant extracts. Molecules 14(6):2016-2031.

Jäger S, Winkler K, Pfuller U, Scheffler A. 2007. Solubility studies of oleanolic acid and betulinic acid in aqueous solutions and plant extracts of Viscum album L. Planta Med 73(2):157-162.

Kirby J, Keasling JD. 2009. Biosynthesis of plant isoprenoids: perspectives for microbial engineering. Annu Rev Plant Biol 60:335-355.

Kratzer S, Schuller HJ. 1997. Transcriptional control of the yeast acetyl-CoA synthetase gene, ACS1, by the positive regulators CAT8 and ADR1 and the pleiotropic repressor UME6. Mol Microbiol 26(4):631-641.

This article is protected by copyright. All rights reserved 
Kuo R-Y, Qian K, Morris-Natschke SL, Lee K-H. 2009. Plant-derived triterpenoids and analogues as antitumor and anti-HIV agents. Nat Prod Rep 26(10):1321-1344.

Lang C, Looman AC. 1995. Efficient expression and secretion of Aspergillus niger RH5344 polygalacturonase in Saccharomyces cerevisiae. Appl Microbiol Biotechnol 44(1-2):147156.

Li J, Zhang Y. 2014. Increase of betulinic acid production in Saccharomyces cerevisiae by balancing fatty acids and betulinic acid forming pathways. Appl Microbiol Biotechnol 98(7):3081-3089.

Li J, Zhang Y. 2015. Modulating betulinic acid production in Saccharomyces cerevisiae by managing the intracellular supplies of the co-factor NADPH and oxygen. J Biosci Bioeng 119(1):77-81.

Maury J, Germann SM, Baallal Jacobsen SA, Jensen NB, Kildegaard KR, Herrgard MJ, Schneider K, Koza A, Forster J, Nielsen J and others. 2016. EasyCloneMulti: A set of vectors for simultaneous and multiple genomic integrations in Saccharomyces cerevisiae. PLoS One 11(3):e0150394.

Moses T, Pollier J, Thevelein JM, Goossens A. 2013. Bioengineering of plant (tri)terpenoids: from metabolic engineering of plants to synthetic biology in vivo and in vitro. New Phytol 200(1):27-43.

O'Connell MM, Bentley MD, Campbell CS, Cole BJW. 1988. Betulin and lupeol in bark from four white-barked birches. Phytochemistry 27(7):2175-2176.

Paddon CJ, Westfall PJ, Pitera DJ, Benjamin K, Fisher K, McPhee D, Leavell MD, Tai A, Main A, Eng D and others. 2013. High-level semi-synthetic production of the potent antimalarial artemisinin. Nature 496(7446):528-532.

Perrone GG, Tan S-X, Dawes IW. 2008. Reactive oxygen species and yeast apoptosis. Biochim Biophys Acta 1783(7):1354-1368.

Polakowski T, Stahl U, Lang C. 1998. Overexpression of a cytosolic hydroxymethylglutaryl-CoA reductase leads to squalene accumulation in yeast. Appl Microbiol Biotechnol 49(1):66-71.

Potze L, Di Franco S, Grandela C, Pras-Raves ML, Picavet DI, van Veen HA, van Lenthe H, Mullauer FB, van der Wel NN, Luyf A and others. 2016. Betulinic acid induces a novel cell death pathway that depends on cardiolipin modification. Oncogene 35(4):427-437.

Puder C, Graef H, Thumerer M, Heitzmann M; 2007. Process for the extraction of betulinic acid. US patent 2007/0149490 A1

Ressmann AK, Kremsmayr T, Gaertner P, Zirbs R, Bica K. 2017. Toward a benign strategy for the manufacturing of betulinic acid. Green Chem 19(4):1014-1022.

Salmon M, Thimmappa RB, Minto RE, Melton RE, Hughes RK, O’Maille PE, Hemmings AM, Osbourn A. 2016. A conserved amino acid residue critical for product and substrate specificity in plant triterpene synthases. Proc Natl Acad Sci U S A 113(30):E4407-E4414.

Sandoval CM, Ayson M, Moss N, Lieu B, Jackson P, Gaucher SP, Horning T, Dahl RH, Denery JR, Abbott DA and others. 2014. Use of pantothenate as a metabolic switch increases the genetic stability of farnesene producing Saccharomyces cerevisiae. Metab Eng 25:215-226.

Segura MJ, Meyer MM, Matsuda SP. 2000. Arabidopsis thaliana LUP1 converts oxidosqualene to multiple triterpene alcohols and a triterpene diol. Org Lett 2(15):2257-2259.

Shang F, Wen S, Wang X, Tan T. 2006. Effect of nitrogen limitation on the ergosterol production by fed-batch culture of Saccharomyces cerevisiae. J Biotechnol 122(3):285-292.

Steyer D, Erny C, Claudel P, Riveill G, Karst F, Legras JL. 2013. Genetic analysis of geraniol metabolism during fermentation. Food Microbiol 33(2):228-234.

Tan T, Zhang M, Gao H. 2003. Ergosterol production by fed-batch fermentation of Saccharomyces cerevisiae. Enzyme Microb Technol 33(4):366-370.

This article is protected by copyright. All rights reserved 
Tang W, Xie C, Wang Z, Wu S, Feng Y, Wang X, Wang J, Gong J. 2014. Solubility of androstenedione in lower alcohols. Fluid Phase Equilib 363:86-96.

Teixeira MC, Raposo LR, Mira NP, Lourenco AB, Sa-Correia I. 2009. Genome-wide identification of Saccharomyces cerevisiae genes required for maximal tolerance to ethanol. Appl Environ Microbiol 75(18):5761-5772.

Tippmann S, Scalcinati G, Siewers V, Nielsen J. 2016. Production of farnesene and santalene by Saccharomyces cerevisiae using fed-batch cultivations with RQ-controlled feed. Biotechnol Bioeng 113(1):72-81.

van den Berg MA, de Jong-Gubbels P, Kortland CJ, van Dijken JP, Pronk JT, Steensma HY. 1996. The two acetyl-coenzyme A synthetases of Saccharomyces cerevisiae differ with respect to kinetic properties and transcriptional regulation. J Biol Chem 271(46):28953-28959.

van Hoek P, de Hulster E, van Dijken JP, Pronk JT. 2000. Fermentative capacity in high-celldensity fed-batch cultures of baker's yeast. Biotechnol Bioeng 68(5):517-523.

Verstrepen KJ, Van Laere SD, Vercammen J, Derdelinckx G, Dufour JP, Pretorius IS, Winderickx J, Thevelein JM, Delvaux FR. 2004. The Saccharomyces cerevisiae alcohol acetyl transferase Atf1p is localized in lipid particles. Yeast 21(4):367-377.

Westfall PJ, Pitera DJ, Lenihan JR, Eng D, Woolard FX, Regentin R, Horning T, Tsuruta H, Melis DJ, Owens A and others. 2012. Production of amorphadiene in yeast, and its conversion to dihydroartemisinic acid, precursor to the antimalarial agent artemisinin. Proc Natl Acad Sci USA 109(3):E111-E118.

Wick W, Grimmel C, Wagenknecht B, Dichgans J, Weller M. 1999. Betulinic acid-induced apoptosis in glioma cells: A sequential requirement for new protein synthesis, formation of reactive oxygen species, and caspase processing. J Pharmacol Exp Ther 289(3):1306-1312.

Willis RB, Montgomery ME, Allen PR. 1996. Improved method for manual, colorimetric determination of total Kjeldahl nitrogen using salicylate. J Agric Food Chem 44(7):18041807.

Winkelnkemper T. 2011. Key performance indicators for economic downstream process development [PhD Thesis]. Dortmund: TU Dortmund University.

Wriessnegger T, Pichler H. 2013. Yeast metabolic engineering - targeting sterol metabolism and terpenoid formation. Prog Lipid Res 52(3):277-293.

Zangar RC, Davydov DR, Verma S. 2004. Mechanisms that regulate production of reactive oxygen species by cytochrome P450. Toxicol Appl Pharmacol 199(3):316-331.

Zhang D-M, Xu H-G, Wang L, Li Y-J, Sun P-H, Wu X-M, Wang G-J, Chen W-M, Ye W-C. 2015. Betulinic acid and its derivatives as potential antitumor agents. Med Res Rev 35(6):11271155.

Zhou C, Li J, Li C, Zhang Y. 2016. Improvement of betulinic acid biosynthesis in yeast employing multiple strategies. BMC Biotechnol 16(1):59.

Zuco V, Supino R, Righetti SC, Cleris L, Marchesi E, Gambacorti-Passerini C, Formelli F. 2002. Selective cytotoxicity of betulinic acid on tumor cell lines, but not on normal cells. Cancer Lett 175.

This article is protected by copyright. All rights reserved 
Table I. Comparison of productivities, volumetric, and specific concentrations of betulinic acid producing S. cerevisiae BA4 in batch and fed-batch cultivations. Total triterpenoid concentrations correspond to the sum of lupeol, betulin, betulinic aldehyde, and betulinic acid.

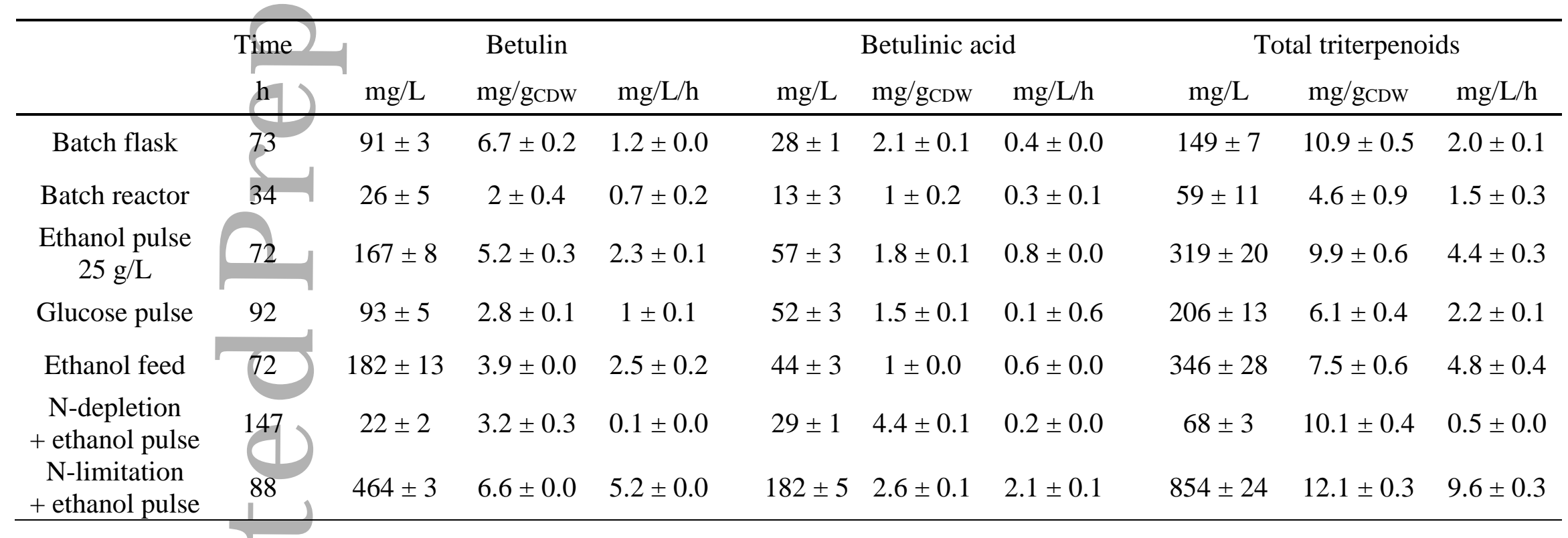

This article is protected by copyright. All rights reserved 
Table II. Triterpenoid yield on applied carbon substrate from fed-batch bioreactor cultivations. Yield (Y) is expressed as \% Cmol product per Cmol substrate. B-betulin, BA-betulinic acid, Tot-sum of all oxidized lupeol products.

\begin{tabular}{cccc}
\hline & YB/S $_{\text {Ba }}$ & Y $_{\text {BA }}$ & Y $_{\text {Tot/S }}$ \\
\hline Batch reactor & 0.11 & 0.05 & 0.24 \\
Ethanol pulse (25 g/L) & 0.23 & 0.08 & 0.44 \\
Glucose pulse & 0.08 & 0.04 & 0.18 \\
Ethanol feed & 0.36 & 0.08 & 0.68 \\
N-depletion + EtOH pulse & 0.04 & 0.06 & 0.44 \\
N-limitation + EtOH pulse & 0.25 & 0.10 & 0.47 \\
\hline
\end{tabular}

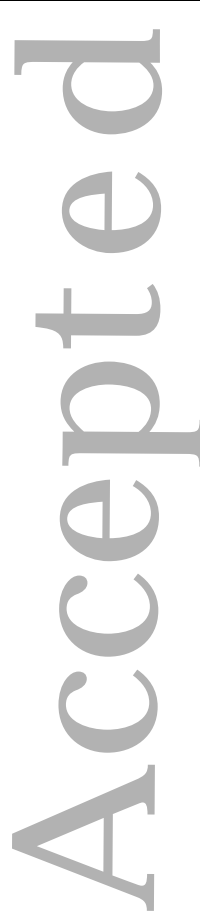

This article is protected by copyright. All rights reserved 
Table III. Recovery of lupeol, betulin, and betulinic acid under optimized precipitation conditions. The area percentage of the component peaks in the chromatogram might be interpreted as the purity of the molecule. The average values of three different fermentation batches and duplicate precipitation experiments are presented. The phase ratio was set to $1.2 \mathrm{~mL}$ Acid $/ \mathrm{mL}_{\text {Extract }}$ at $3 \mathrm{~h}$ resting time.

\begin{tabular}{cccc}
\hline Antisolvent & Component & Recovery [\%] & Area-\% in chromatogram \\
\hline \multirow{3}{*}{ Water } & Lupeol & $-*$ & $\leq 2$ \\
& Betulin & $90 \pm 4$ & $53 \pm 10$ \\
& Betulinic acid & $86 \pm 4$ & $9 \pm 1$ \\
\hline \multirow{3}{*}{$1 \mathrm{M} \mathrm{HCl}$} & Lupeol & $-*$ & $24 \pm 11$ \\
& Betulin & $195 \pm 34$ & $41 \pm 4$ \\
& Betulinic acid & $104 \pm 13$ & $7 \pm 1$ \\
\hline
\end{tabular}

*Not calculated as lupeol was not calibrated

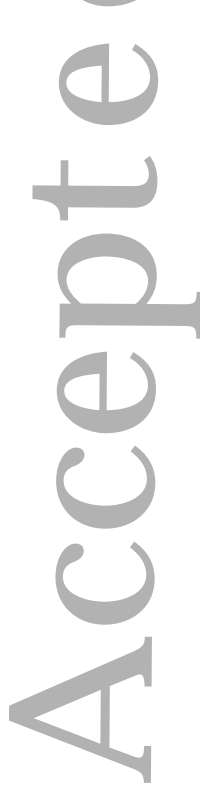

This article is protected by copyright. All rights reserved 


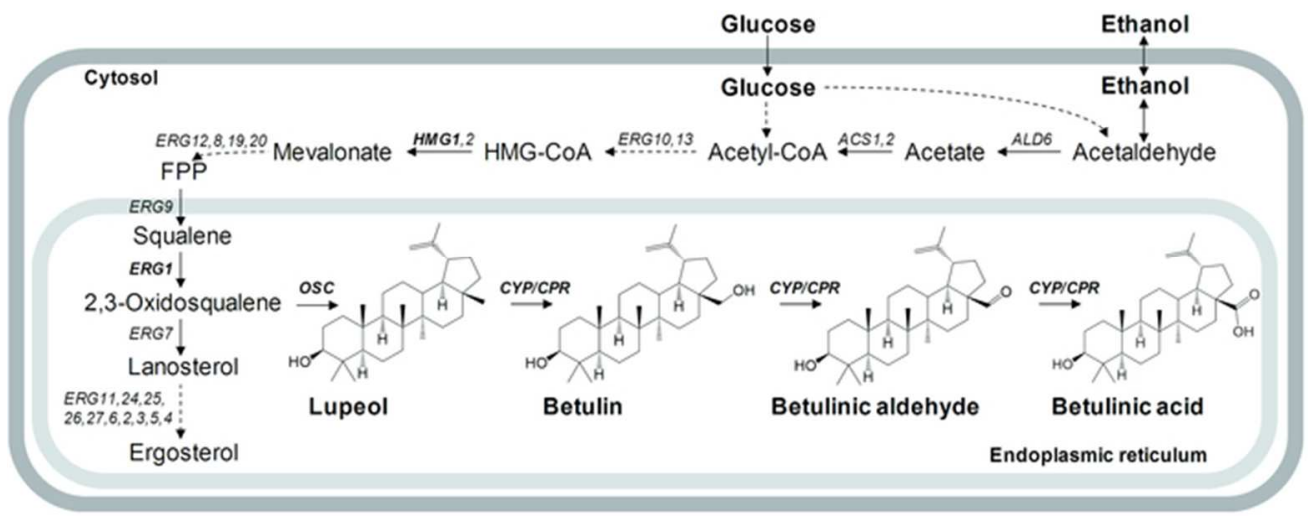

Figure 1. Schematic of the heterologous betulinic acid pathway in S. cerevisiae. 


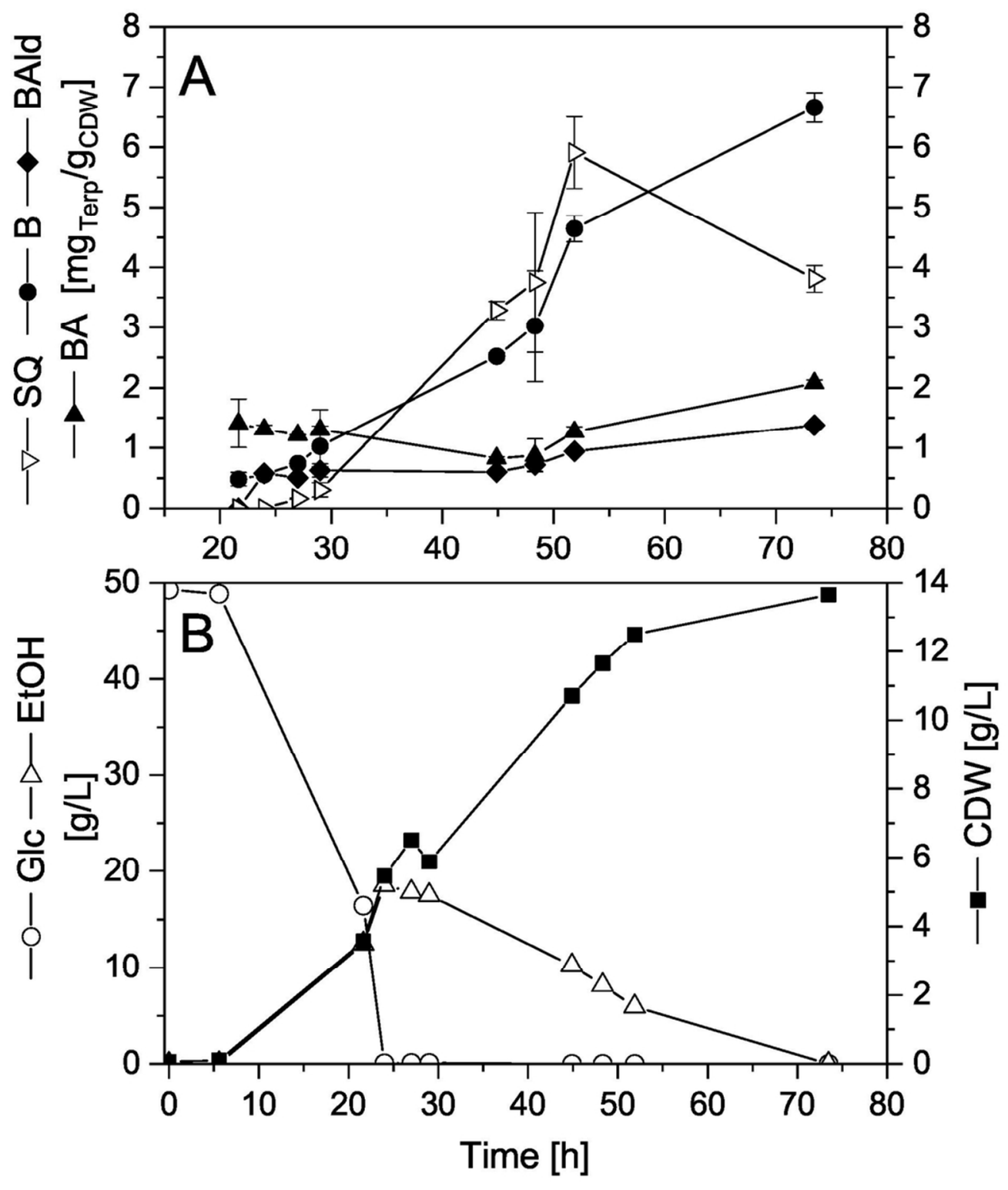

Figure 2. Specific triterpenoid (A) and extracellular metabolite and biomass concentrations (cell dry weight, CDW) (B) during batch shake flask cultivation of $S$. cerevisiae BA4 in WM8+ medium with $50 \mathrm{~g} / \mathrm{L}$ glucose. For reasons of clarity lupeol is excluded but shown in figure S2. SQ-squalene, B-betulin, BAld-betulinic aldehyde, BA-betulinic acid. 

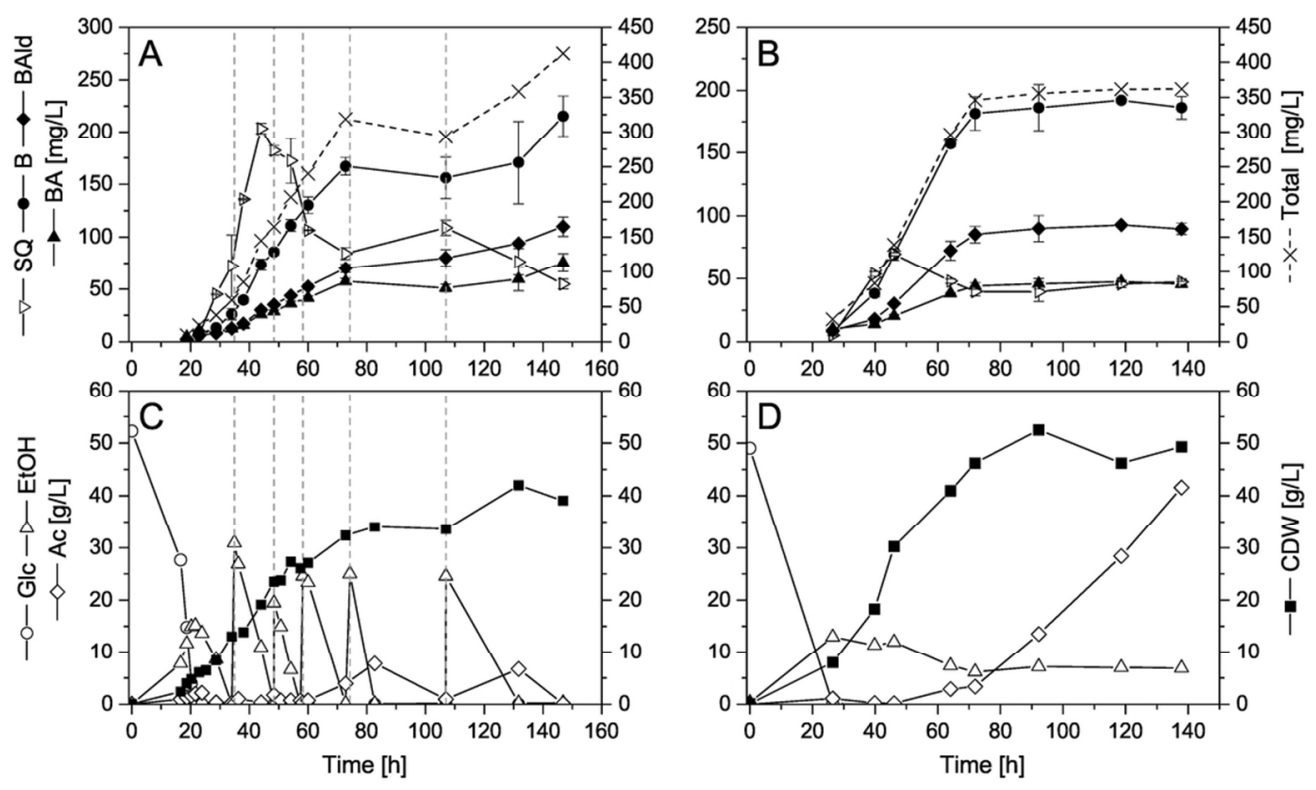

Figure 3. Product and extracellular metabolite concentrations during fed-batch cultivation of $S$. cerevisiae BA4 in WM8+ medium. Cultivations were performed with a DO-triggered ethanol pulse fed-batch $(A, C)$ and feed-back loop controlled ethanol fed-batch at constant ethanol concentration of $7 \mathrm{~g} / \mathrm{L}(\mathrm{B}, \mathrm{D})$. For reasons of clarity lupeol is excluded and shown in figure S3. SQ-squalene, B-betulin, BAld-betulinic aldehyde, BAbetulinic acid, Glc-glucose, EtOH-ethanol, Ac-acetate, CDW-cell dry weight. Dashed lines indicate pulsed addition of $25 \mathrm{~g} / \mathrm{L}$ ethanol. 

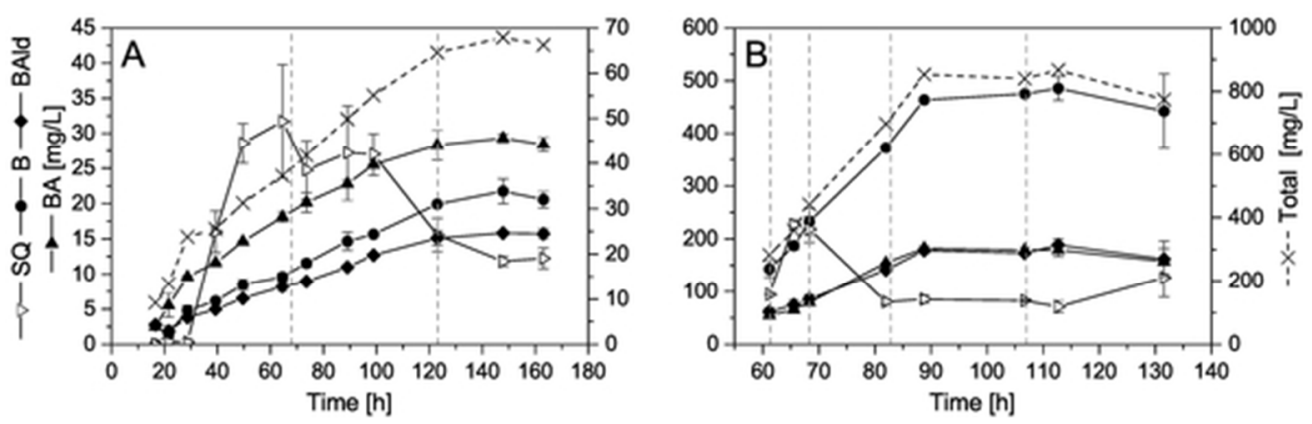

Figure 4. Product concentrations during nitrogen-limited cultivation of S. cerevisiae BA4. Growth in WM8+ medium under nitrogen depletion and subsequent ethanol pulsing (A). Resting cell fermentation with ethanol pulse feeding of cells grown in glucose fed-batch and transferred into nitrogen free WM8+ medium (B). Time starts with the initiation of the glucose fed-batch. For reasons of clarity lupeol is excluded but shown in figure S4. SQ-squalene, B-betulin, BAld-betulinic aldehyde, BA-betulinic acid. Dashed lines indicate pulsed addition of $25 \mathrm{~g} / \mathrm{L}$ ethanol. 

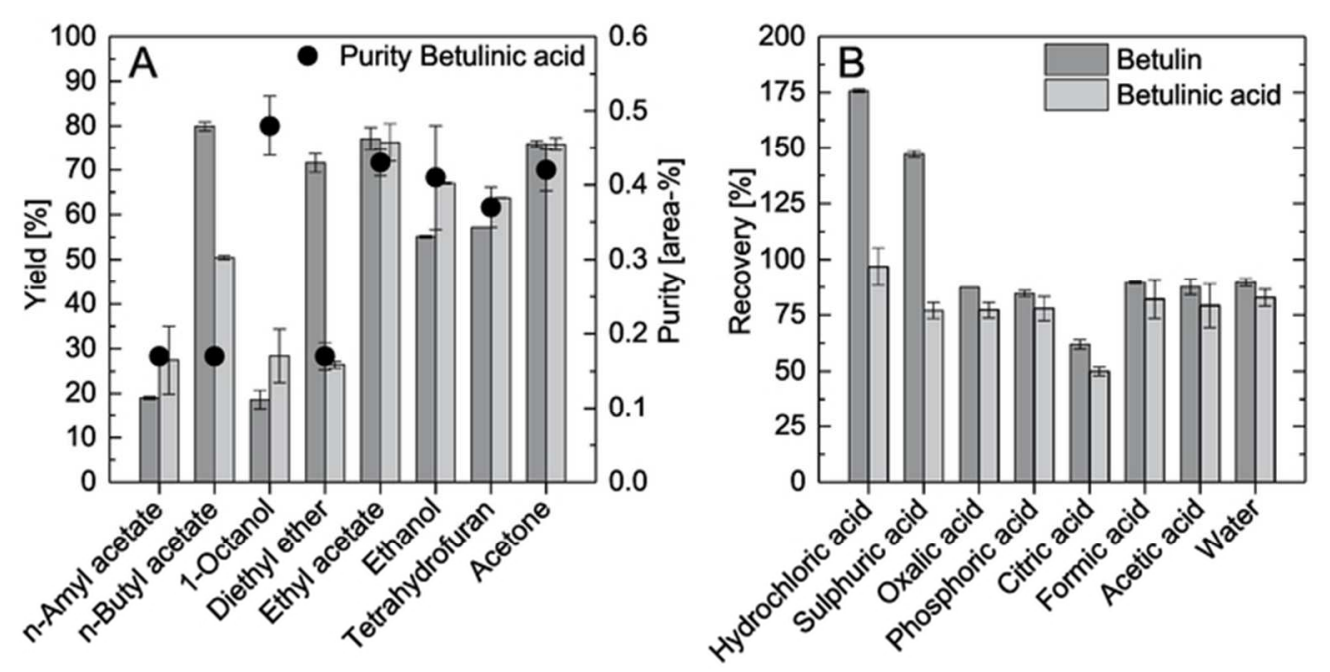

Figure 5. Extraction yield and purity of different water miscible and immiscible solvents for the recovery of betulin and betulinic acid (phase ratio $10 \mathrm{~g}$ solvent $/ \mathrm{g}_{\mathrm{CDW}}$, for $15 \mathrm{~h}$ at $25^{\circ} \mathrm{C}$ ) (A). Dependency of the antisolvent acidity on the recovery of betulin and betulinic acid (B). Acetone was used as extractant mixed with $1 \mathrm{M}$ acid at a ratio of $0.9 \mathrm{~mL}_{\mathrm{Acid}} / \mathrm{mL}_{\text {Extract }}$ at $25^{\circ} \mathrm{C}$ for precipitation. Antisolvents are ordered by decreasing acidity (strong to weak acid). 

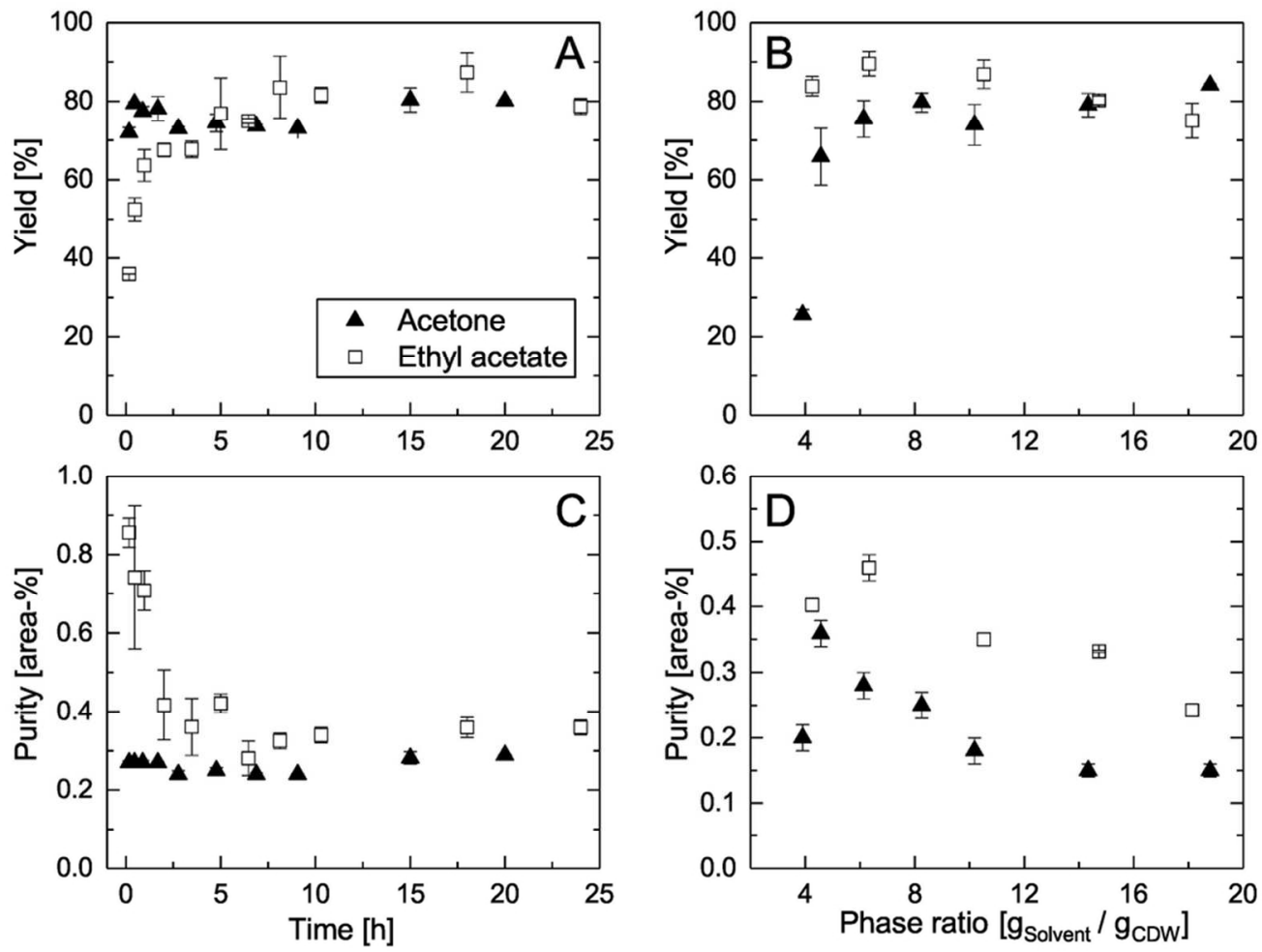

Figure 6. Comparison of betulinic acid yield (A, B) and purity (C, D) obtained with acetone and ethyl acetate as extractant in dependence on extraction time (phase ratio $10 \mathrm{gsolvent} / \mathrm{g}_{\mathrm{CDw}}$, at $25^{\circ} \mathrm{C}$ ) and phase ratio at $25^{\circ} \mathrm{C}$. 


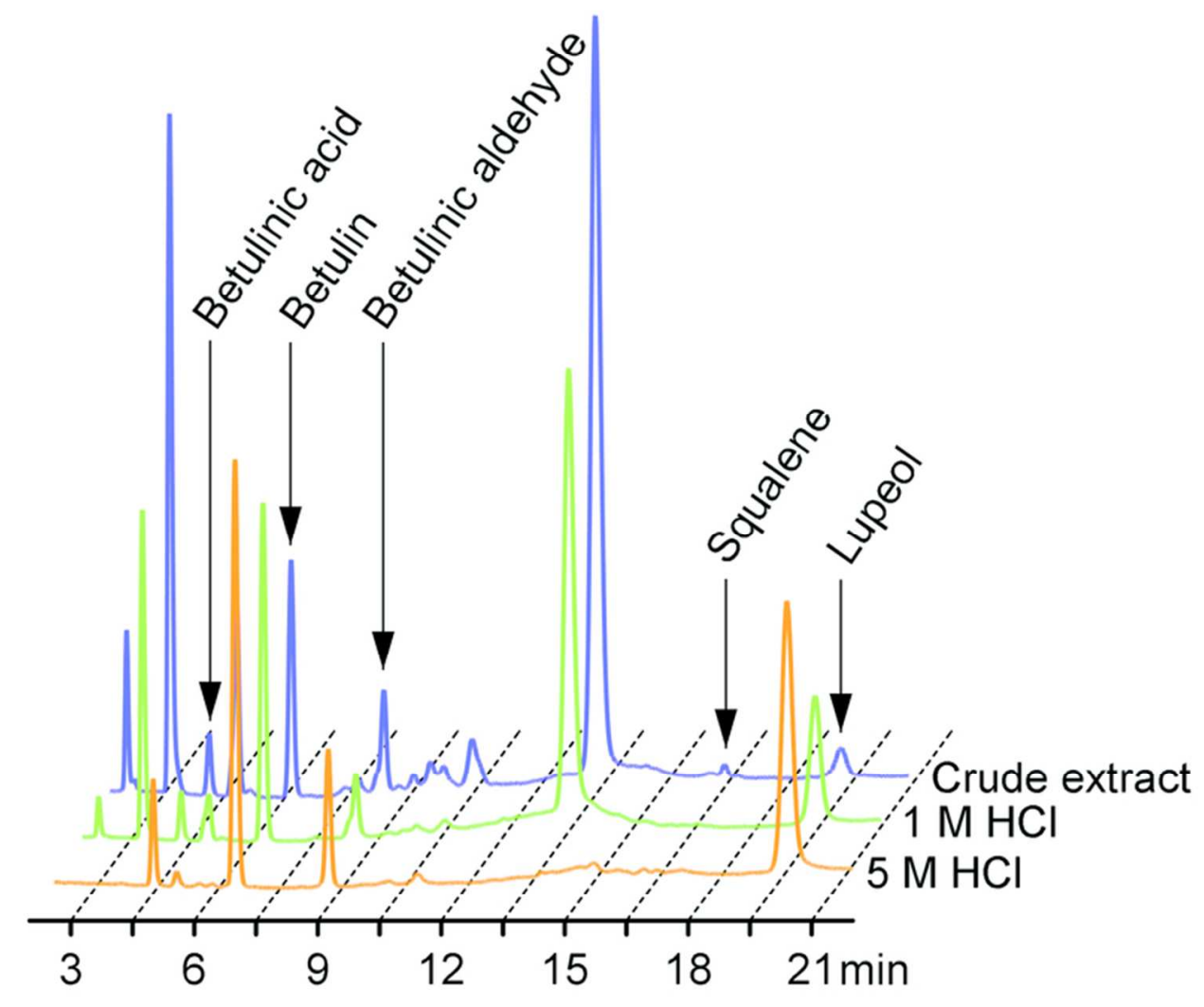

Figure 7. Chromatograms of the crude acetone extract and of the resolved precipitates treated with $1 \mathrm{M}$ and $5 \mathrm{M} \mathrm{HCl}$. 